\section{Conceptual advantages of using pupil to limbus ratio over absolute pupil diameter}

Sir,

We have read with interest the article of Mojumder et al. on the use of pupil to limbus ratio to measure anisocoria ${ }^{[1]}$ and we would like to share our experience on this topic:

Some studies have demonstrated that digital photography is a very convenient tool for the measurement of pupil diameter in ophthalmic practice. It offers several advantages over other methods (inexpensive, accurate, more repeatable than other techniques, provides long lasting documentation, and eases masked observations). ${ }^{[2]}$ However to take absolute measures of pupil diameter, a ruler or a template should be included in the photo, and care should be taken to its placement and orientation to avoid parallax effects. Otherwise, only relative measures of pupil diameter can be taken. Using relative measures of pupil diameter (pupil to limbus ratio), simplifies the process of taking the photos (it is not necessary to include extra elements in the picture) and could have important advantages over using absolute measurements in different situations:

- Intra-subject comparisons: This method is impeccable to monitor changes on pupil diameter on the same subject. As Mojumder et al. demonstrate in their article, this is a really convenient approach to monitoring pupil changes in the UCI. It can also be useful in the differential diagnosis of anisocoria (to monitor pupil change when apraclonidine, cocaine, or pilocarpine 0.125 tests are performed)

- Inter-subject comparisons: To compare pupil diameters among different subjects this method has also important advantages over the methods that use absolute measurements. Pupil diameter is correlated with limbus diameter. A 6-mm-pupil is probably maximum mydriasis in a subject with 8 -mm-corneas, but it is not certainly maximum mydriasis in a subject with 13-mm-diameter-corneas. In the first case, pupil diameter is $75 \%$ of the maximum pupil diameter whereas in the second case pupil diameter is $46 \%$ of the maximum pupil diameter

- Defining anisocoria: Expressing pupil diameter as a percentage of limbal diameter makes possible a more logical definition of anisocoria. As pupil diameter has a wide distribution (young myopic subjects have bigger pupils than old hyperopic subjects), ${ }^{[3]}$ we find the classical definition of anisocoria very rigid. A $0.5 \mathrm{~mm}$ difference should be considered significant in a subject with $2.5 \mathrm{~mm}$ pupils, but it is probably insignificant in a patient with 6-mm-pupils

- Comparing photopic and scotopic pupils in the same subject: In our experience, using absolute measures, anisocoria tends to be greater under scotopic conditions (not only on Horner syndrome, also in physiologic anisocoria and anisocoria related to parasympathetic lesions). This fact is probably due to bigger scotopic pupils. This bias could be avoided using the relative change in a pupil to limbus ratio between photopic and scotopic pupil.

In summary, we agree with the authors. Pupil to limbus ratio is not only a very convenient method to measure pupils. It also has many conceptual advantages.

\section{Financial support and sponsorship \\ Nil.}

\section{Conflicts of interest}

There are no conflicts of interest.

Julio González Martín-Moro ${ }^{1,2}$, Belén Pilo de la Fuente ${ }^{3}$, Fernando Gomez Sanz ${ }^{1,4}$

${ }^{1}$ Department of Ophthalmology, University Hospital of Henares, ${ }^{2}$ Department of Medicine, Francisco de Vitoria University, ${ }^{3}$ Department of Neurology, University Hospital of Getafe, ${ }^{4}$ Department of Optics II, Complutense School of Optometry, Madrid, Spain

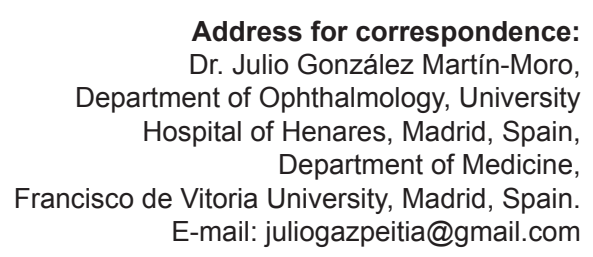

\section{References}

1. Mojumder DK, Patel S, Nugent K, Detoledo J, Kim J, Dar N, et al. Pupil to limbus ratio: Introducing a simple objective measure using two-box 
method for measuring early anisocoria and progress of pupillary change in the ICU. J Neurosci Rural Pract 2015;6:208-15.

2. Twa MD, Bailey MD, Hayes J, Bullimore M. Estimation of pupil size by digital photography. J Cataract Refract Surg 2004;30:381-9.

3. Hashemi H, Yazdani K, Khabazkhoob M, Mehravaran S, Mohammad K, Fotouhi A. Distribution of photopic pupil diameter in the Tehran eye study. Curr Eye Res 2009;34:378-85.

This is an open access article distributed under the terms of the Creative Commons Attribution-NonCommercial-ShareAlike 3.0 License, which allows others to remix, tweak, and build upon the work non-commercially, as long as the author is credited and the new creations are licensed under the identical terms.

\begin{tabular}{|l|l|}
\hline \multicolumn{2}{|c|}{ Access this article online } \\
\hline Quick Response Code: & Website: \\
\hline & www.ruralneuropractice.com \\
\cline { 2 - 2 } & \\
\hline
\end{tabular}

How to cite this article: Martín-Moro JG, de la Fuente BP, Sanz FG. Conceptual advantages of using pupil to limbus ratio over absolute pupil diameter. J Neurosci Rural Pract 2015;6:625-6. 